\title{
O design na criação de produtos a partir de madeiras nativas descartadas.
}

Marlon Ferraz Moreira;

Clara Santana Lins Cerqueira

\section{resumo:}

Este trabalho visa analisar como o design pode contribuir na reutilização de madeiras nativas do Brasil, provenientes do descarte voraz da indústria moveleira. Para tanto, o trabalho se respaldou na análise das madeiras descartadas por uma indústria - que ficará sob sigilo - de móveis situada na cidade de Ubá, Minas Gerais, hoje considerada um dos maiores polos moveleiros do Brasil. Ao aplicar metodologias e ferramentas de design, a pesquisa aborda a importância do ecodesign e da reciclagem dessa matéria-prima na criação de novos produtos. A solução final do projeto foi a criação de uma linha de tábuas de corte para cozinha, proposta pelo projeto "Árvore de Minas". Assim, foram utilizadas as técnicas da marcenaria artesanal como fonte de inspiração criativa, voltadas para a valorização e resgate da produção manufatureira muito presente no início da história da cidade de Ubá enquanto polo moveleiro.

palavras-chave:

design; madeira; reciclagem; ecodesign; artesanal 


\section{Introdução}

De acordo com os dados preliminares, fornecidos pela ABIMÓVEL (Associação Brasileira das Indústrias do Mobiliário) em 2017, a produção de móveis no mundo chegou a US\$ 421 bilhões em 2016, em comparação com os dados de 2015, houve um crescimento de $1,1 \%$.

Ao comparar os blocos econômicos mundiais, encontramos no topo da lista o continente Asiático que detém 53,6\% da produção mundial e se destaca como maior produtor moveleiro, graças ao grande desempenho produtivo da China, que detém 39,2\% e também é responsável por $28,3 \%$ das exportações para o mundo (ABIMÓVEL, 2017).

O setor moveleiro brasileiro só aparece na frente de países como Rússia e África do Sul, com uma capacidade produtiva de $3,4 \%$ em relação a produção mundial, e por sua vez, todos os produtos são consumidos no país, restando apenas $0,4 \%$ em comércio de exportação. O Brasil é constituído por cerca de 13.500 micros, pequenas e médias empresas e, em 2016, produziu em média, 430,6 milhões de peças no mercado de móveis (ABIMÓVEL,2017).

Ao observar os dados oferecidos pela ABIMÓVEL em 2017, pode-se perceber a importância que a produção de móveis de madeira tem no setor de mobiliário caracterizando a importância do setor para a economia. Em contrapartida, existe um descarte excessivo dessa matéria-prima, e assim, órgãos responsáveis pela fiscalização ambiental de indústrias de grande impacto pressionam as mesmas a se preocuparem e se enquadrarem às exigências.

Portanto, se faz necessário repensar as técnicas de produção que geram grandes desperdícios, bem como a reutilização dessa matéria-prima descartada por essas indústrias. É importante ter em vista, a criação de uma ideologia que visa a diminuição dos descartes. Ao observar os consumidores atuais, percebe-se uma preocupação dos mesmos com a sustentabilidade dos produtos. De acordo com Manzini e Vezzoli (2008), "o green consumerism é um fenômeno já consolidado e que desempenhou um papel importante para deslocar a questão ambiental do terreno da denúncia para o terreno da economia e do mercado ((MANZINI ; VEZZOLI, 2008, p. 85)". Dessa forma, o consumidor se sente incentivado e engajado a consumir produtos sustentáveis visando benefícios para um bem comum.

$\mathrm{O}$ pensamento em design, suas ferramentas e metodologias de projeto, podem ser uma alternativa para o desenvolvimento de práticas mais sustentáveis dentro das indústrias como, por exemplo, repensar a matéria-prima descartada, planejar as técnicas a serem utilizadas no processo para um reaproveitamento mais coerente da matéria-prima em relação ao mercado e as possibilidades de produção.

Segundo Arruda (2009), o designer deve estabelecer uma relação clara com seu consumidor através do produto, sensibilizando-o para as questões ambientais e sustentáveis. E, por fim, o designer demonstra seu potencial inovador às indústrias quando alia ferramentas do ecodesign - como, por exemplo, o Ciclo de Vida do Produto, Base de Dados - no processo de criação gerando soluções estéticas e funcionais exclusivas para determinados nichos e público elencando, portanto, um diferencial competitivo através do design.

O reaproveitamento da matéria-prima descartada em produtos que podem ser usados e até comercializados como móveis, objetos decorativos, adornos entre outros, podem reduzir os impactos ambientais. Diversas empresas já compreendem que o slogan de "empresa sustentável" pode trazer inúmeros benefícios à mesma como, por exemplo, a redução de custos econômicos e impactos ambientais, aumento da competitividade no desenvolvimento de novos produtos e serviços, gerando inovações tecnológicas radicais (MANZINI ; VEZZOLI, 2008, p. 82 e 83). A reciclagem é um processo que se enquadra em qualquer nicho social e que pode gerar novos empregos para a população, beneficiando também renda para artesãos, marceneiros e decoradores.

Portanto, a pesquisa teve como objetivo propor uma solução para o descarte indevido de madeiras de uma determinada indústria ${ }^{1}$ situada na cidade de Ubá, através da aplicação do design como ferramenta estratégica para a produção de novos produtos da empresa "Árvore de Minas". Para tanto, a metodologia utilizada consistiu na coleta de dados sobre a quantidade de madeira descartada pela "Indústria X" da cidade de Ubá, analisar as possibilidades de uso, verificar o público alvo que

\footnotetext{
${ }^{1}$ Por motivos éticos, foi definido um nome fictício acerca da indústria pesquisada: "Indústria X".
} 
valoriza a reutilização de matéria-prima descartada para a produção de novos produtos e, por fim, propor produtos a partir desse descarte.

\section{0 surgimento do Arts and Crafts}

A Revolução Industrial teve seu início em 1760 e, desde então, impulsionou diversas transformações sociais, culturais e políticas. A produção em massa desencadeou uma série de mudanças em vários setores sociais, e a maneira pela qual a sociedade passaria a consumir mudaria para sempre.

A produção e comercialização de produtos foram ganhando outra perspectiva. Antes, com mão de obra artesanal, os produtos demoravam a serem fabricados, pois sua produção passava por processos manuais, onde o mestre artesão tratava o produto quase como uma obra de arte (PAZZINATO; SENISE, 2004). Todo o processo era meticuloso e a peça era comercializada por um valor mais oneroso, ou seja, o produto era menos acessível para a maioria das pessoas. Dessa forma, a economia girava de maneira lenta, atendendo a apenas uma parcela da população da época. Para Eric Hobsbawm (2003), a industrialização gerava demanda em vez de apenas suprir as necessidades já existentes.

A invenção da máquina a vapor, pelo escocês James Watt gerou milhares de empregos e mobilizou milhões de camponeses para os centros urbanos, sendo um marco para o desenvolvimento da Inglaterra. O produto deixou de ser "precioso", pois todo o processo de produção foi restruturado para uma produção em massa.

Entretanto, a mercadoria, neste processo, perdia identidade e valor. A linha de produção era regida por trabalhadores que manipulavam tecnologias de ponta e foi permitindo aumento significativo na produção das indústrias e custos cada vez menores, por conta da rapidez nos processos e da cadeia produtiva, que dispunha de menos mão de obra.

$\mathrm{Na}$ Revolução Industrial e, portanto, com o surgimento da automação, a sociedade passou por várias mudanças socioculturais, não só caracterizado pelo consumo voraz, que passou a fazer parte do dia a dia dos indivíduos, mas também da relação dos mesmos com o trabalho.

A comercialização era um ciclo, onde os próprios produtores eram obrigados a trabalhar longos períodos e, a pouca forma de lazer que tinham, era consumir os produtos que os mesmos produziam. Houve, portanto, uma grande desvalorização do trabalho artesanal para dar lugar ao novo sistema fabril, e a classe que se beneficiava de uma série de problemas socioeconômicos, ambientais e políticos, era a burguesia (TEIXEIRA; SOUZA, 1985).

Assim, o movimento Arts and Crafts nasce desse contexto de insatisfação com a massificação dos produtos que, na visão de August Pugin, Jonh Ruskin e Willams Morris ${ }^{2}$ degradou a estética dos produtos e a consciência ética, "apontando para o custo humano e sacrifício envolvidos num sistema social que exigia e produzia esses bens (HESKETT, 2012, p. 20)".

Eles $^{3}$ fizeram muito para despertar a consciência da Inglaterra vitoriana e tiveram grande impacto no exterior, mas a influência de suas ideias sobre a indústria foi limitada, reduzindo-se essencialmente a uma nostalgia da cultura artesanal do passado, sem referência aos esforços para reconhecer e aperfeiçoar a situação existente (HESKETT, 2012, p.20)

Por isso, o movimento surgiu com a intenção de trazer de volta o valor estético nos produtos, onde seus locutores valorizavam o design aliado ao artesanato demarcando mais qualidade do que quantidade.

A principal característica do movimento Arts and Crafts, idealizava a beleza "pura e simples", e desejava que as criações fossem belas e funcionais, assim, o desenvolvimento dos produtos ignorava os meios de produção em massa da época e envolviam estilos medievais e clássicos em suas características.

Mais tarde a iniciação de novos outros movimentos como o Art Nouveau e o Art Déco, bem como o estudo da união do design às artes e os meios de produção. Porém, o insucesso desse

\footnotetext{
${ }^{2}$ Grandes influenciadores do movimento Arts and Crafts.

${ }^{3} \mathrm{O}$ autor se refere a August Pugin John Ruskin, Willams Morris.
} 
movimento foi substituído mais tarde pelos movimentos citados acima, pois seu processo, caracterizado como "anti-industrial", eram concebidos e executados pelos artesãos, implicando em um processo longo e demorado, por vezes oneroso, até a finalização do produto final. Assim, pouco a pouco, o movimento perdia força e espaço mais uma vez para a produção em massa, que era a proposta iniciada pelo sistema capitalista da época (HESKETT, 2012).

Por fim, o movimento Arts and Crafts perdeu o ímpeto por volta da Primeira Guerra, mas o ideal artesanal do movimento ainda inspira diversos designers da atualidade.

\section{A sustentabilidade nas indústrias}

Para Santos (2009), "a sustentabilidade requer um processo de reposicionamento dos modos de vida da sociedade e isso implica em um processo de aprendizado coletivo que é, por natureza, lento e complexo" (SANTOS, 2009, p.14).

A sustentabilidade deixou de ser um termo desconhecido há algumas décadas e passou a ser uns dos principais assuntos em estudo e discussão em todo o mundo. Atualmente essa pauta ainda permanece nos holofotes e se tornou comum para toda sociedade. Contudo, o planeta ainda continua sofrendo as consequências da exploração indevida e exacerbada dos recursos naturais fazendo com que a biodiversidade não consiga ter tempo suficiente param se renovar, levando a natureza a um colapso.

Para Papanek (2002), "a ecologia e o equilíbrio ambiental são os esteios básicos de toda a vida humana na Terra; não pode haver vida nem cultura humanas sem ela" (PAPANEK, 2002, p.31). As consequências desse descaso causam problemas, na maioria das vezes, irreparáveis como as inundações, escassez de água, extinções da fauna e flora, etc.

É sabido que as indústrias têm grande parte da responsabilidade pela poluição global, é preciso usar não apenas as ferramentas de marketing, para concentrar através da propaganda a "onda da sustentabilidade", mas procurar desenvolver processos capazes de utilizar os recursos naturais sabiamente. Atualmente esse modelo de produção ameaça não apenas a natureza, a fauna e a flora, mas a humanidade, pois haverá o esgotamento de recursos essenciais para diversas atividades indispensáveis à sobrevivência humana. Dessa forma, o design voltado às pesquisas e práticas de aspectos sustentáveis vem sendo uma agente de diálogo entre processos produtivos e sustentabilidade nas empresas, minimizando o desperdício de matéria-prima, projetando produtos mais duráveis, repensando a cadeia produtiva, atendendo as necessidades e demandas do mercado (BATISTA; NETO, 2020).

O próprio tema da sustentabilidade é o primeiro dos novos valores universais em potencial. E nos propõe, de fato, o valor da responsabilidade nos confrontos das gerações futuras e, consequentemente, o objetivo de não prejudicar os equilíbrios ambientais em que a nossa vida e a esperança futura de vida na terra se baseiam. (MANZINI; VEZZOLI, 2002, p.57)

Os consumidores, por sua vez, com o passar dos anos estão buscando mais informações sobre o tema, e estão cada vez mais conscientes ao escolherem produtos que refletem suas preferências de consumo. Há a cobrança ativa para que as empresas tenham responsabilidade no lugar onde atuam. Progressivamente, mais pessoas começam a se interessar pelo assunto e pesquisam a fundo o histórico, das empresas e seus projetos ligados a sustentabilidade. O pensamento sustentável tende a beneficiar todo o ecossistema social, tanto no que tange a economia, empresas e indústrias, quanto a população e a sociedade de maneira geral, que passa a entender a sustentabilidade como uma forma de gerar novos negócios e oportunizar a comunidade local.

Durante muito tempo acreditou-se que a sustentabilidade custava caro, porém essa ideia atualmente está ultrapassada. Atualmente, grandes e pequenas empresas percebem que ser socialmente e ambientalmente responsáveis têm se tornado uma vantagem altamente competitiva, pois ao adotar práticas sustentáveis elas experimentam a redução nos custos do serviço oferecido e atraem a preferência dos consumidores (BATISTA; NETO, 2020). Assim foi a experiência de um dos executivos de uma das maiores empresas brasileira de cosméticos, Natura. Uma gestão sustentável passou a ser parte fundamental do planejamento da empresa para garantir seu futuro e sucesso no mercado 
(CUNHA, 2019). Mesmo sendo um desafio, representa novas oportunidades de negócio e crescimento, entre a sociedade, a indústria e a economia, a fim de preservar os recursos naturais ainda disponíveis na natureza.

\section{A iniciativa "Árvore de Minas"}

A empresa "Árvore de Minas" nasce de uma iniciativa particular do pesquisador e designer, no ano de 2016 na cidade de Ubá situada no estado de Minas Gerais, Brasil.

Ubá é uma cidade com 101.519 mil (IBGE, 2010) habitantes, sua economia gira em torno do polo moveleiro, que conta com 306 unidades produtoras, gerando mais de 18.084 mil empregos diretos, que são compostos por municípios, além de Ubá, Astolfo Dutra, Divinésia, Dores do Turvo, Guarani, Guidoval, Guiricema, Senador Firmino, Silverânia, Tabuleiro, Tocantins e Visconde do Rio Branco, sendo este polo o maior produtor de Minas Gerais, produzindo 27 milhões de peças, e ajudando ativamente o Estado a ter uma participação de 6.7 bilhões de reais na produção de móveis, juntamente com outros dois polos, Belo Horizonte e Carmo do Cajurú.

Juntamente com o mentor e sócio da "Árvore de Minas", José Mario, foi iniciado uma busca incessante por inspirações de mobiliários. Foram feitos vários desenhos, misturando-se as experiências de ambos, onde a teoria e a prática começavam a fazer sentido e gerava algumas possibilidades para as ideias. Os primeiros esboços eram brutos até demais, e não tinham nenhum planejamento estético. A marcenaria naquele momento se tornou um ponto positivo, apesar de singela, os maquinários e fornecedores eram suficientes para conseguir criar quaisquer protótipos e fazer daquele espaço um ambiente de execução para o que era proposto naquele momento, mobiliário decorativo em madeira maciça.

Assim, no mesmo período, os sócios, Marlon e José Mario, já estavam testando um novo produto que, para eles, era algo inovador, que iria agregar e gerar muito valor aos produtos: a resina epóxi. Mais tarde foi substituída pela Resina Poliéster, sua utilização era exclusivamente automotiva, e a ideia, naquele momento, era testar qual seria a reação da química com a madeira. Não existia quase nada na internet, sua aplicação era confusa e precisavam de fornecedores nacionais.

O projeto da Árvore de Minas foi iniciado com a escolha de um desenho do mobiliário feito pelos sócios. Foi selecionado um sketch que remetia um tabuleiro de xadrez/dama, a idealização e desenvolvimento se deu pela escolha dos materiais. Foi selecionada a madeira de eucalipto, como forma circular e a madeira de Tauari, em formato quadrado, disposta superficialmente de forma organizada, preenchida posteriormente pela resina de preto.

O processo prático foi baseado em corte e colagem das madeiras e depois pelo preenchimento total dos espaços vazios pela resina líquida e catalisada. Após alguns minutos, ocorria a solidificação do material. Posteriormente, foi submetida por um processo de acabamento, onde várias lixas eram aplicadas em sua superfície. A escolha dos pés palitos, se deu para intensificar a característica retrô no produto, e por fim a aplicação de verniz fosco em toda mesa, para resistência e durabilidade do mobiliário.

A aceitação da resina com a madeira de Eucalipto foi um sucesso, obteve-se um resultado surpreendente e seria reutilizado também nos próximos produtos da empresa.

Em 2017, os idealizadores da "Árvore de Minas" lançaram a primeira coleção (Figura 1) que se chamava "Minas Gerais", era composta por 8 produtos, entre eles mesas de centro, mesas laterais, aparadores e posteriormente luminárias.

Figura 1: Primeiros Protótipos da coleção Minas Gerais da coleção Minas Gerais

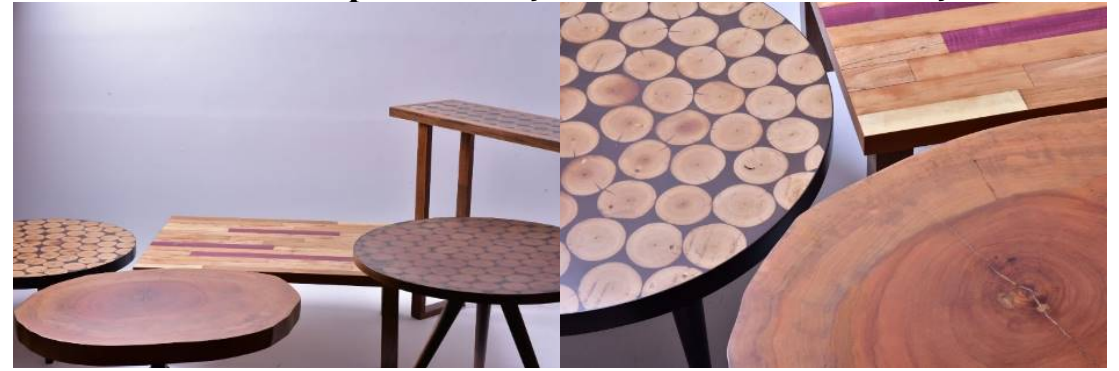

Fonte: arquivo do autor, 2017. 
O principal objetivo da coleção era a valorização da madeira em sua forma natural, realçando suas características mais marcantes, como o seus veios, sua robustez presente nas formas e sua pigmentação original. Portanto, a coleção se destacou pelo alto nível de acabamento que prevaleceu nos processos, aliando o rústico da peça ao sofisticado. A coleção "Minas Gerais" é destinada para o público que aprecia o trabalho com madeira maciça e optam pelo mobiliário que seja ao mesmo tempo rústico, com toques de sofisticação e contemporaneidade.

\section{Proposta para a coleção Minas Kitchen}

A “Árvore de Minas" ao incorporar o design no processo de planejamento e produção teve como resultado o desenvolvimento de produtos a partir da reciclagem das madeiras descartadas.

Com o bum de programas culinários, além da etapa de Imersão a seguir, percebeu-se uma oportunidade de mercado para quem deseja utensílios domésticos e, aqui mais precisamente, tábuas para corte. Essa pesquisa teve como público alvo a geração Millenials como norteador para o desenvolvimento estético e funcional da nova coleção a ser criada. A inspiração no movimento Arts and Crafs, teve como objetivo o desenvolvimento do processo criativo que valorizasse métodos da marcenaria artesanal na execução dos produtos aqui propostos.

Para tanto, nesta etapa, foi imprescindível a pesquisa bibliográfica, a pesquisa de campo e a utilização de ferramentas de design para chegar a uma solução projetual com a finalização do protótipo.

\subsection{Campo de Estudo}

A coleção "Minas Kitchen", nasce a partir da reutilização de madeiras descartadas da Indústria X, situada no polo moveleiro de Ubá.

A indústria em questão é reconhecida nacionalmente pelo grande mix de produtos, sua participação no mercado nacional se estende até as regiões sul, sudeste, centro-oeste e nordeste do país, especializada na produção de mobiliários para salas e dormitórios.

A oportunidade para a realização da pesquisa se deu pelo contato do pesquisador com a Indústria $\mathrm{X}$, ao participar de algumas negociações na compra de matéria prima para a "Árvore de Minas." Foi observado um volume considerável de descarte de madeiras, que poderiam ser reciclados e, assim, transformados em novos produtos.

As madeiras eram separadas pelos colaboradores, de forma que eram priorizadas as que tinham maior comprimento, se a madeira continha bichos, maiores espessuras. Depois dessa seleção, as que não se enquadravam nos requisitos eram descartadas.

O pesquisador tomou a iniciativa para descobrir o que a empresa fazia com a madeira descartada (Figura 2). E assim, foi descoberto que a mesma saia sem custos para padarias utilizarem como combustão em fornos. Logo, foi feito um pedido para o recolhimento da remessa que estava disposta no momento, liberada sem nenhum custo.

Figura 2: Madeiras descartadas

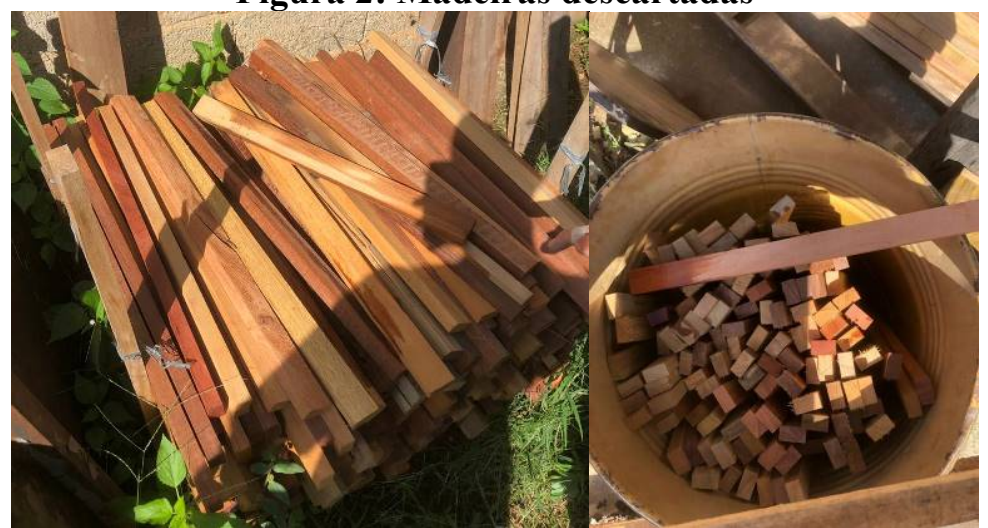

Fonte: arquivo do autor, 2019. 
As madeiras descartadas eram de 4 tipos: Roxinho, Muiracatiara, Jequitibá e Angelin, todas elas são madeiras nativas do Brasil e de alta resistência. Algumas dessas madeiras têm características especiais e únicas como a madeira Roxinho, por exemplo, apesar de apresentar uma coloração castanho-escuro assim que é cortada adquire o tom roxo intenso ou de violeta púrpura. A exposição ao ar é o que faz com que a madeira mude sua cor. A Muiracatiara apresenta duas propriedades principais: aparência das faixas rajadas irregulares e alta resistência, com cores marrom claro, ou marrom escuro, e o seu cerne de cor vermelho-escuro ou castanho-avermelhado (GONZAGA, 2006). A madeira Jequitibá é tem o seu aspecto da casca externa marrom-escuro, rugosa, rígida, com depressões. Já a casca interna é avermelhada. E, por fim, a Angelin é caracterizada por cores intensas de bege-amarelado, amarelo, vermelho a marrom escuro. Sua superfície é lisa e lustrosa (GONZAGA, 2006).

\subsection{Metodologia e Ferramentas de design para o desenvolvimento "Minas Kitchen"}

Para a realização do projeto aqui proposto, foram utilizadas ferramentas e metodologias de design e de mercado para o entendimento geral do contexto do projeto, bem como a sua viabilização e prototipação. Foram elas respectivamente: Brienfing ${ }^{4}$; a Identificação do Público Alvo; Identificação dos Concorrentes Diretos e Indiretos; criação de Pesronas; Painéis imagéticos de Estilo de Vida e Semântico para o público alvo, além de painéis para a Inspiração e Conceito do projeto; Imersão no campo de estudo; Definição dos Requisitos de Projeto; Gerações de Alternativas; Modelagem e Prototipação e Protótipos finalizados.

\subsection{Metodologia}

A metodologia escolhida se deu a partir da mescla de duas metodologias: a primeira baseada no livro "Projeto de Produto" do autor Mike Baxter e a segunda com o auxílio do livro de Ana Veronica Pazmino, "Como Se Cria. A mescla resultou na seguintes etapas a serem seguidas neste trabalho (Figura 3): Interação, Entendimento, Revisão da Oportunidade, Criação e Implementação.

Figura 3: Metodologia do autor.

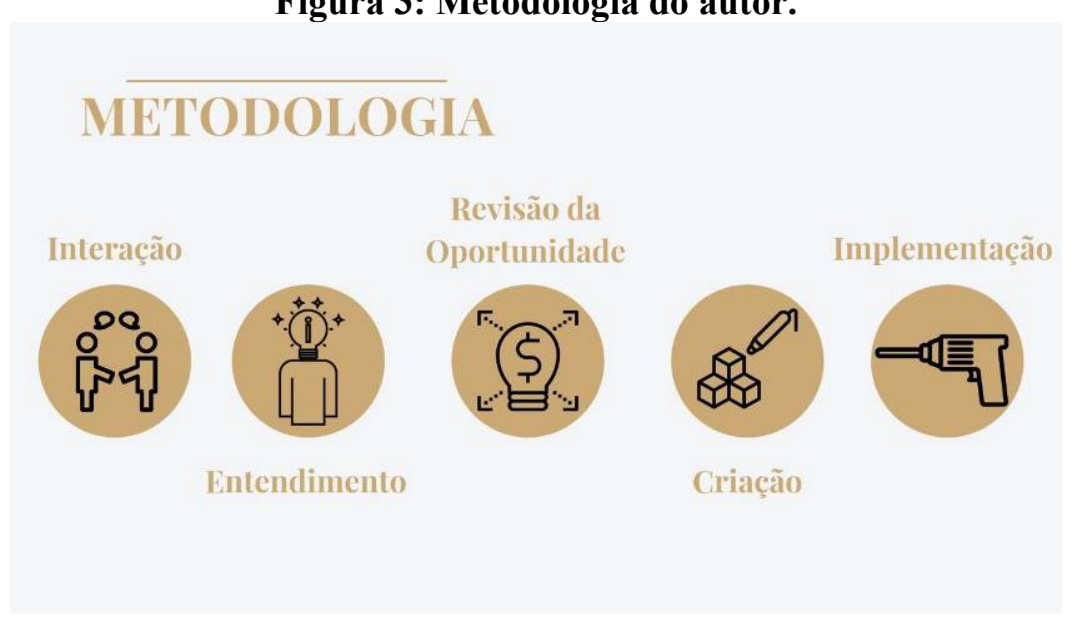

Fonte: arquivo do autor, 2019.

\footnotetext{
${ }^{4}$ Para Phillips (2009), é muito comum nos projetos de design a utilização do briefing para a sua execução e, uma de suas características fundamentais, uma ferramenta deve ser necessariamente escrita e nunca verbalmente falada.

Sendo indispensável em qualquer etapa do desenvolvimento do projeto, o uso dessa ferramenta tem como objetivo sintetizar as informações levantadas e separar as mesmas para um maior entendimento das demandas com o intuito de propor soluções viáveis: que atendam ao público alvo e, logo, o mercado consumidor.
} 
Nas etapas de "Interação" e "Entendimento" foi importante o contato com a "Indústria X" e alguns funcionários. A partir disso foi possível fazer uma coleta de dados sobre o descarte das madeiras, para entender os reais motivos da sobra de matéria-prima, além da realização de entrevistas, imersões no contexto, pesquisa exploratória e análise dos dados obtidos.

Após a análise completa das duas primeiras etapas, deu-se início a etapa de "Revisão da Oportunidade", que visou a possiblidade de criar de novos produtos através das madeiras descartadas e, assim, foi decidido fazer objetos para cozinha, tendo em vista uma série de fatores como: públicoalvo, tamanho das madeiras descartadas e a tendência crescente no mercado de cozinha. Para auxiliar esse processo, foram também utilizadas ferramentas como "mapa mental" e "personas".

A etapa de "Criação" consistiu em fazer exaustivamente as geração de alternativas e utilizar o software em 3D para definição de acabamentos, formas e cores; e a "Implementação" consistiu no desenvolvimento de protótipos, com a colaboração da Árvore de Minas.

\subsection{Identificação do público alvo}

No primeiro momento, a escolha do público obteve-se pela análise de gerações. Ao levantar os dados necessários para validação da oportunidade e traçar por meio das pesquisas bibliográficas um público que desejasse objetos que fossem desenvolvidos, par a coleção "Minas Kitchen", sobre a perspectiva da sustentabilidade e a valorização de processos artesanais em sua produção. A geração Millennials se destacou pela personalidade sobre as demais, tendo como ponto positivo o apreço por tais produtos.

A geração Millenials, representa cerca de 70 milhões de pessoas no Brasil que nasceram entre os anos de 1977 e 1999 (O GLOBO, 2019).

Entretanto, segundo um estudo desenvolvido pelo GoogleBrasil (2017), existem comportamentos diferentes dentro da mesma geração, sendo possível uma divisão entre o lado extremo dos nascidos no início da geração, Old Millennials, comparado aos nascidos no final, New Millennials. A divisão dessa geração foi marcada por dois grandes acontecimentos, o primeiro deles veio com a popularização dos smartsphones em 2007, aumentando o acesso à informação em qualquer hora e lugar, oferecendo a cultura da velocidade e consequentemente do imediatismo, ou seja, os nascidos no início geração tiveram que se adaptar a esse novo modo de comunicação e aprender a usar a tecnologia na fase da adolescência. Estes também sofreram com uma instabilidade econômica com a quebra de grandes instituições globais, que culminou em uma série de desempregos e alta na inflação, ao contrário do que estava acontecendo no final dos anos 90 e início dos 2000, prosperidade e crescimento acentuado na economia. Já os nascidos no final da geração, tiveram sua infância contagiada pelas novas tecnologias, assimilando e aprendendo com mais rapidez e naturalidade os novos modelos de comunicação globalizada.

Ao estudar o comportamento dos Old Millenialls, de acordo com a pesquisa feita pelo MILLENNIAL MARKETING, um em cada quatro Millennialls são pais atualmente, e $65 \%$ dos homens acreditam que, assim como as mulheres, têm igual responsabilidade sobre seus filhos. Isso aponta para uma geração que vem se transformando o pensamento tradicional em relação a questões socioculturais.

\subsection{Personas}

Ao entender o público-alvo, analisar os concorrentes e previamente definir o produto, foi a vez de traçar e identificar o perfil do cliente para a coleção "Minas Kitchen". Assim, foi utilizada a ferramenta de Persona para compreender as características, sentimentos, anseios e desejos por parte deste público.

\subsection{Painéis}

Por meio da escolha e entendimento do público-alvo, a geração Old Millennials, foram obtidas informações de comportamento, estilo de vida, padrões de consumo, e relações que caracterizam de maneira mais concreta os Old Millennials. O uso de painéis é fundamental e caracterizado pelo uso de imagens para auxiliar na compilação das informações do público alvo. Segundo Pazmino (2015), o "uso de imagens para representar o público-alvo é um auxílio para que o processo cognitivo do 
designer e da equipe de projeto perceba de forma nítida o público a ser atendido pelo projeto" PAZMINO, 2015).

O Painel de Estilo de Vida ilustrado na Figura 4, intenciona explorar o lado maduro da geração, com a perspectiva dos desejos explorados através do estudo da geração dos Old Millennials. A busca por momentos que transmitem experiências como viajar para um lugar novo, ou conhecer pessoas; o uso da tecnologia para o desenvolvimento do conhecimento e comunicação; a interação com os amigos semanalmente; a escolha por cozinhar seu próprio alimento e a compra por alimentos saudáveis e a pratica da leitura como hobby.

Figura 4: Painel Estilo de Vida e Painel Semântico do público-alvo, respectivamente.

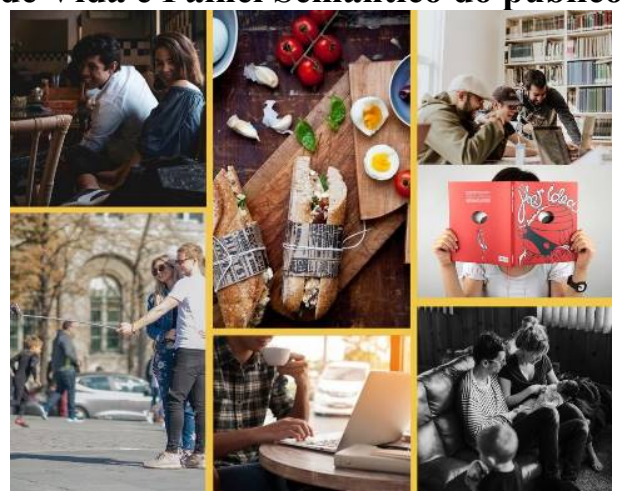

Fonte: UNSPLASH.COM, 2019.

O Painel Semântico ilustrado na Figura 5, representa que apesar de ter passado a infância sem a tecnologia, à geração conheceu os smartphones em sua adolescência e conseguiram adaptar-se rapidamente e a usam como principal fonte comunicadora, sabendo manipulá-las muito bem. São pessoas, em sua maioria, otimistas que buscam uma segurança, normalmente gostam de ter experiências diferentes, valorizam produtos que estimulam elas.

Figura 5: Painel Semântico do público-alvo.

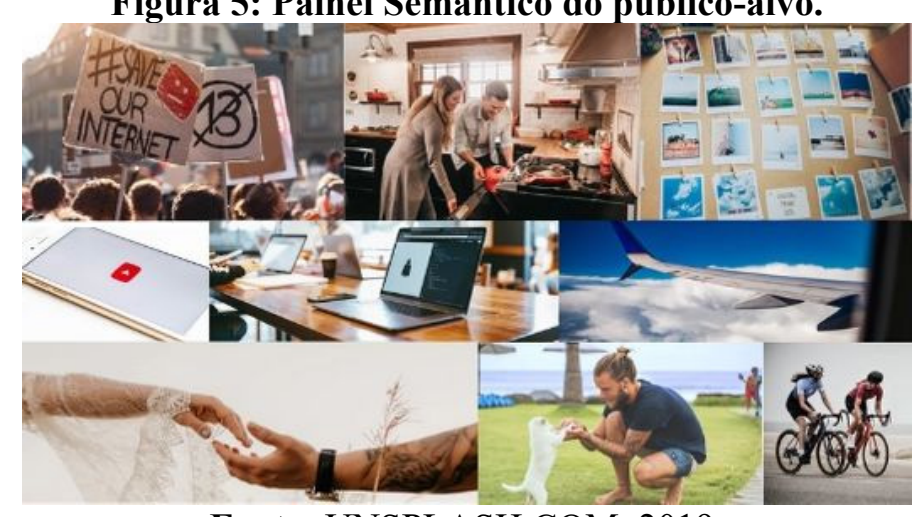

Fonte: UNSPLASH.COM, 2019.

\subsection{Inspiração e Conceito}

O desenvolvimento da coleção deve-se ao aperfeiçoamento da madeira reaproveitada como principal fonte criativa, entender como explorar esse material e utilizá-lo através da marcenaria para criar produtos que fossem atraentes para o público-alvo, como ilustra a Figura 6 a seguir. 
Figura 6: Painel Inspiração.

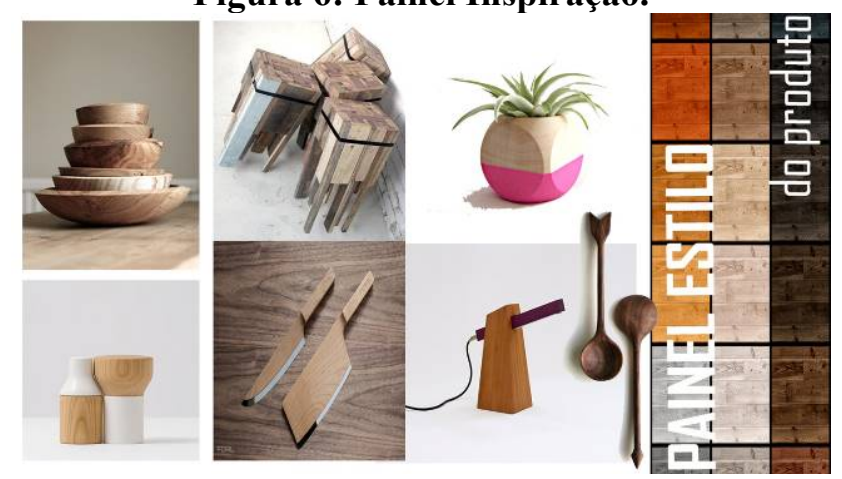

Fonte: elaborado pelo autor, 2019.

O conceito (Figura 7) partiu da necessidade de aumentar a satisfação do público alvo ao cozinhar com o produto proposto, por isso, foram estabelecidas cinco ações fundamentais para ser aplicadas no projeto: a união com os amigos, a madeira universal, interatividade com o alimento, comida fresca e memória afetiva.

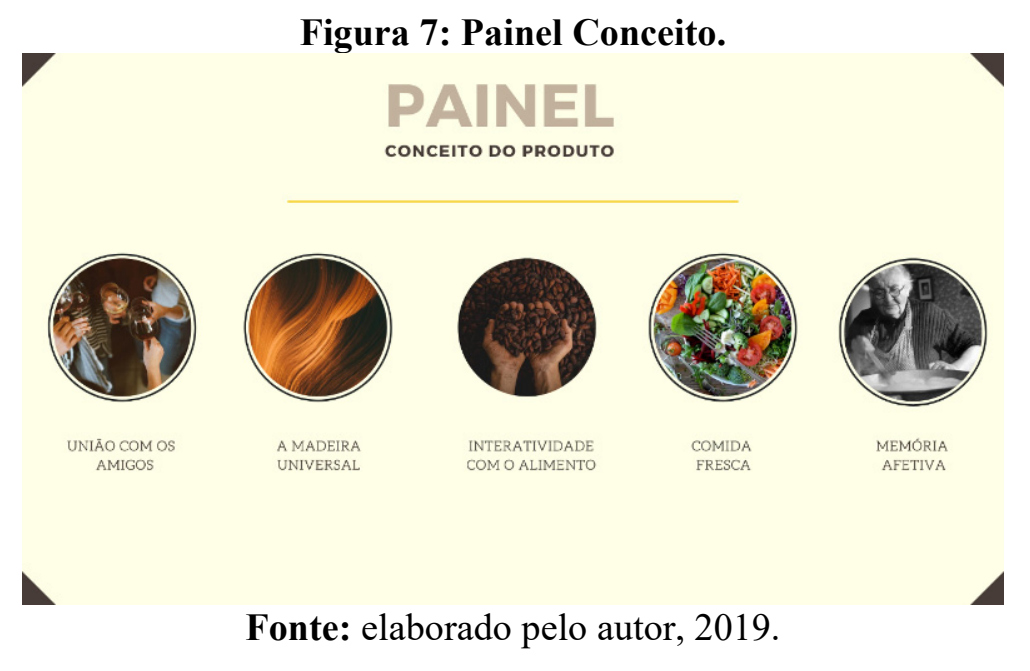

I. União com os amigos: a companhia de alguém na hora de se alimentar gera muito mais satisfação, elevando os níveis de endorfina no corpo.

II. A madeira universal: a madeira será a principal responsável por quase todo trabalho estético ao utilizar a naturalidade de suas formas, principalmente as suas cores, robustez e "imperfeições", como forma de valorizá-la.

III. Interatividade com o alimento: ao preparar uma refeição é importante que o cozinheiro estabeleça uma boa interatividade com o alimento que está sendo preparado, para isso, os utensílios são fundamentais.

IV. Comida Fresca: se tratando de comida bem preparada, um grande diferencial é ter todos os alimentos o mais frescos possível, isso realça o sabor e aumenta uma preocupação na hora da refeição. V. Memória afetiva: uma memória afetiva pode se desenvolver a partir de uma percepção sensorial como um odor, um som, uma cor, desde que tal percepção esteja ligada a um momento afetivo importante. O resgate da memória afetiva pode ser traduzido no conceito do produto, como a "comida de vó", pois grande parte da geração Millenials, teve uma aproximação muito grande com os avós.

\subsection{Imersão}

Para conseguir compreender melhor todo o contexto que envolvia o projeto, foi pesquisada uma série de lugares (Figura 8) que teriam uma junção de comida, cozinha e a geração Old Millenials. Dentre esses lugares, o Mercado Novo, inaugurado no ano de 1960, na cidade de Belo Horizonte, foi uma surpresa positiva, pois o local foi restaurado e reinaugurado recentemente, em 2018, com lojas de 
quitutes, bares e restaurantes, onde existem os conceitos de sustentabilidade - como o uso de assentos e mesas improvisados em paletes - e fortalecimento de produtos mineiros (GALVÃO, 2019).

Figura 8: Imersão no Mercado Novo - BH e restaurantes de diversas cidades do interior de Minas Gerais, respectivamente.

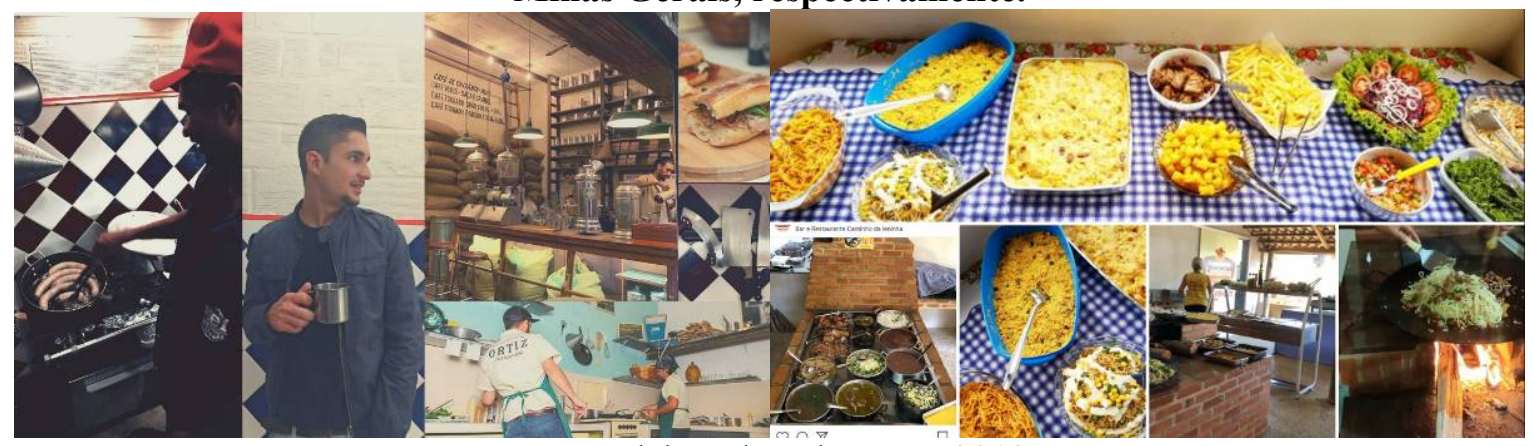

Fonte: elaborado pelo autor, 2019.

Portando a imersão foi fundamental para descobrir muitos aspectos importantes para a escolha de qual produto criar, a maioria dos bares e restaurantes tinha suas cozinhas abertas, e isso proporcionava uma proximidade do cliente com os chefes de cozinha, podendo também ser observado o preparo da comida, enquanto o consumidor interagia com os amigos.

Através dessa imersão foi importante observar dois fatos: o primeiro, o relacionamento entre as pessoas enquanto se alimentavam. Foi identificado que o prazer de comer acompanhado era mais satisfatório. Já o segundo, era o prazer dos cozinheiros frente a arte de cozinhar em ambientes abertos. Foi importante perceber os movimentos e os utensílios mais utilizados para efetuar as tarefas dentro da cozinha.

Dentre todas as cozinhas observadas, existia um objeto que se repetia em todos os estabelecimentos, a tábua de corte. Na maioria das vezes, eram de madeira, dotadas de funções diversas: tanto para o corte de variados tipos de alimentos (carne, legumes, frutas, laticínios, etc), quanto para servir porções aos clientes.

\subsection{Definição dos requisitos de projeto}

Entender o público e seu comportamento foi fundamental, para a sistematização conceitual do produto. Sendo assim, foi decidido requisitos obrigatórios necessários para execução da coleção, sendo eles:

I. Usabilidade: o uso como forma de aproximação do usuário com o produto, focando na experiência do mesmo ao cozinhar, ou servir, comunicando ora leveza nas formas e cores, ora ressaltando a robustez do material utilizado.

II. Estético: um produto que tenha como característica principal a estética natural da madeira, valorizando a madeira nativa brasileira.

III. Fabricação: o processo de fabricação da coleção Minas Kitchen, visa uma produção mais próxima do artesanal, com o auxílio da empresa Árvore de Minas para a implementação do projeto. A sua execução se deu através de maquinários simples e próprios de uma marcenaria tradicional.

IV. Descarte: por se tratar de produtos feitos de madeira, o descarte desses objetos agride menos o meio ambiente.

V. Compostagem: ao se tratar de um produto orgânico, a madeira serve para a utilização de fertilizantes orgânicos na agricultura e pecuária, por exemplo.

VI. Eco Ponto: desenvolvimento municipal, onde a prefeitura sede um espaço para o descarte desse material para posteriormente destinar a um final correto, sendo utilizado na maioria das vezes para a produção de carvão vegetal. 


\subsection{Gerações de alternativas}

Após a pesquisa de referencial bibliográfico e imersão, decidiu-se que a tábua de corte era um produto ideal para ser fabricado. Portanto, foi desenvolvido uma série de gerações de alternativas que possibilitou a experimentação de formas e tamanhos de tábuas.

O trabalho feito nessa etapa foi para conhecer os tamanhos reais das tábuas já utilizadas comumente nas cozinhas convencionais, a proposta era decidir uma forma e tamanho que envolvia uma boa ergonomia e usabilidade, respeitando os tamanhos das madeiras descartadas, já que o plano de corte proporciona um maior aproveitamento de madeiras, um dos objetivos propostos no presente trabalho, explorando formas que gerasse ainda menos desperdícios do material descartado.

\subsection{Modelagem e prototipação}

Após a escolha dos desenhos para o desenvolvimento das tábuas, onde a preocupação foi aproveitar o máximo de madeira possível deixando o produto em um formato atraente, foi o momento de levar as gerações escolhidas para a modelagem em um software de 3D (Figura 9), possibilitando a aplicação das tonalidades das madeiras, esculpindo melhor as curvas para facilitar no manuseio do produto, já que a geração promove uma percepção de profundidade do objeto.

Assim, as tábuas tomaram formas e sua estética pode ser percebida através das aplicações das tonalidades, onde foi possível brincar com as cores e os veios das madeiras, elevando a percepção do produto na hora de cortar e servir. Vale ressaltar que cada modelo de tábua, foi efetuado um trabalho de marcenaria diferente, portanto, a ordem da madeira no 3D e posteriormente o teste na produção.

Figura 9: Modelagem 3D.

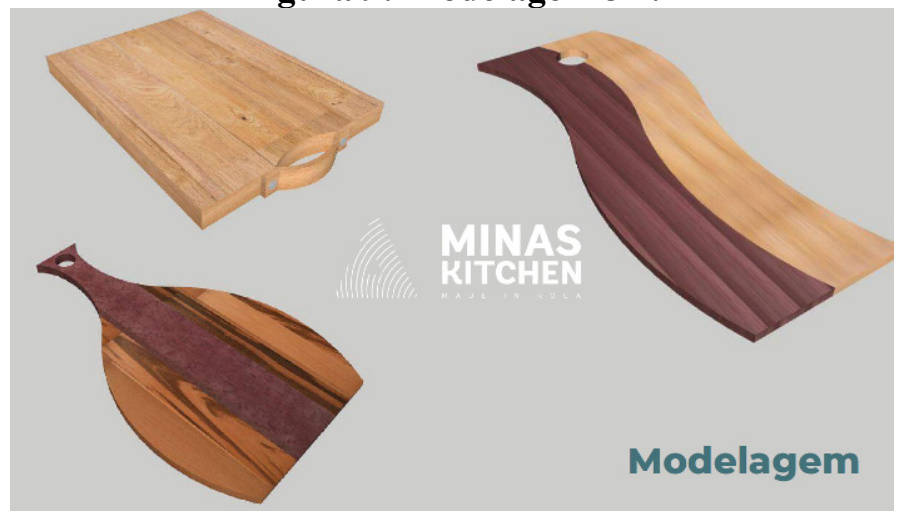

Fonte: elaborado pelo autor, 2019

A partir das modelagens feitas, a introdução da marcenaria no processo de prototipação foi colocada em prática. Os protótipos também são grandes aliados na marcenaria, pois, assim que o modelo 3D foi decidido, a viabilização do produto começa acontecer.

Primeira etapa foi escolher as madeiras descartadas, apesar de todas serem bem conservadas, algumas continham alguns carunchos, impossibilitando em muitos casos o reaproveitamento da matéria prima na hora da fabricação, os tamanhos também foram escolhidos, já que existiam diversos tipos de comprimentos. Após a escolha ser feita, as madeiras foram coladas com cola branca atóxica, própria para colagem de madeiras para alimentação, e posteriormente coladas em moldes até a cura da cola.

Ao colar as madeiras e fazer os testes necessários para ver a fixação da cola, a preparação para o corte foi iniciado, onde primeiramente as peças foram passadas em um "desengrosso", uma maquinaria que tem a função de deixar a peça totalmente plana, acertando assim suas espessuras no tamanho de 2,5 centímetros. Assim, as tábuas foram riscadas conforme os modelos feitos acima, e cortados na serra de fita para ficar no formato desejável.

$\mathrm{O}$ processo de fabricação das tábuas exige alguns testes na madeira, nos pontos de pega e curvas foram necessários os ajustes através de lixas para as quinas permanecerem suaves sem agredir a usabilidade do usuário. 


\subsection{Protótipos finais}

Os protótipos finais (Figura 10 e 11) possibilitaram uma valorização das cores, dos veios naturais da madeira, sua resistência e robustez. A intenção ao planejar quatro tábuas de corte foi para promover os diferentes usos de corte estabelecido pela A Agência Nacional de Vigilância Sanitária (ANVISA), que define que para evitar contaminação cruzada entre os diversos alimentados cortados, é interessante tábuas específicas para cada tipo de alimento. Em cozinhas industriais é muito comum diferenciar as tábuas pela cor como, por exemplo, a tábua branca para queijos e laticínios; azul: peixes e frutos do mar; verde: legumes, verduras e frutas; vermelha: carnes vermelhas; amarela: aves; lilás: assados/embutidos.

Assim, no presente trabalho, também foi desenvolvido quatro tipos diferentes de tábuas que são identificadas por tags, sugerindo o seu uso para o consumidor. Contudo, outros usos podem ser dados por esse consumidor final como, por exemplo, servir alimentos nelas.

Na Figura 10 abaixo temos respectivamente: uma tábua para o corte de pescados e aves; outra para legumes, frutas e verduras; outra para o corte de carnes vermelhas e, por fim, uma a tábua para queijos e laticínios.

As tábuas têm dimensões diferentes ressaltando as diferenças de uso - a tábua para o corte da carne vermelha, por exemplo, é mais robusta e resistente - possibilitando cada produto uma estética única. Além disso, todas as tábuas foram produzidas em processos com ferramentas diversas, com técnicas de produção artesanal, referenciando o estilo Arts and Crafts de produção.

Figura 10: Protótipos finais.

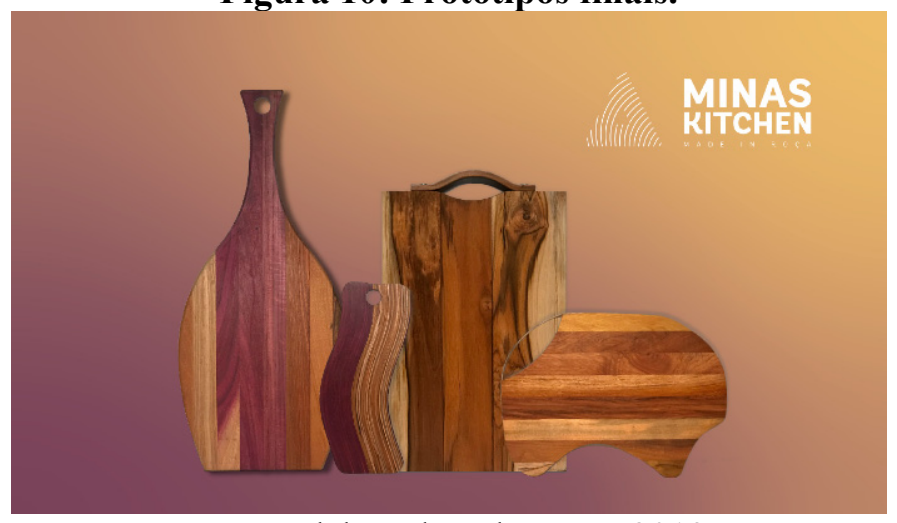

Fonte: elaborado pelo autor, 2019.

Figura 11: Protótipos finais.

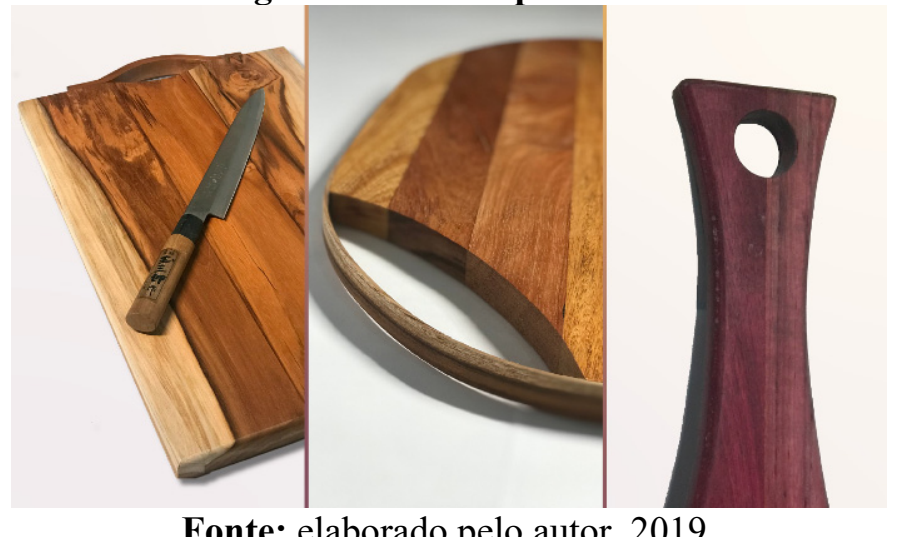

Fonte: elaborado pelo autor, 2019.

\section{Considerações Finais}

A industrialização foi um grande marco social, e vem sendo praticada fortemente até os dias de hoje. É inevitável o forte desenvolvimento que as indústrias têm sobre a sociedade no geral, porém a sua prática deve ser controlada, em vista dos problemas ambientais que seus insumos causam no planeta 
Terra, que impactam negativamente o meio ambiente, bem como os recursos naturais ainda disponíveis.

Dessa forma, existem maneiras diferentes para fazer com que a diminuição do impacto das indústrias no meio ambiente aconteça, dentre elas a inserção do design nas empresas é um meio para melhor organizar a gestão e produção das mesmas, assim visando um crescimento sustentável, que ocasiona uma série de fatores positivos.

Nessa pesquisa, a reutilização de madeiras descartadas de uma indústria moveleira possibilitou a criação de novos produtos, que visou um público alvo que se identificasse com os diálogos acerca da sustentabilidade e do consumo mais sustentável. A proposta teve como resultado repensar o papel do designer enquanto profissional que intermedia o método e o processo, para prospectar a melhoria da qualidade de vida das pessoas.

Através das imersões, foi possível observar alguns requisitos necessários para desenvolver uma boa tábua de corte. A interação próxima com o processo de fabricação proporcionou uma melhor escolha do corte, gerando menos desperdícios, sem prejudicar o estilo artesanal dos produtos.

Sendo assim, foi desenvolvida uma coleção de tábuas de madeiras nativas, em parceria com a marcenaria Árvore de Minas, que intenciona valorizar a união com os amigos e familiares, a valorização natural de cada madeira utilizada, a interação com o alimento a ser preparado, memórias afetivas e nostálgicas a partir da estética, da usabilidade, da resistência a cortes de cada tábua, proporcionando uma experiência única ao se cozinhar.

\section{The Design in creating products from discarded native woods.}

Abstract: This work aims to analyze how design can contribute to the reuse of native wood from Brazil, resulting from the voracious disposal of the furniture industry. To this end, the work was supported by the analysis of the wood discarded by a furniture industry - which will remain confidential - located in the city of Ubá, Minas Gerais, today considered one of the largest furniture hubs in Brazil. When applying design methodologies and tools, the research addresses the importance of ecodesign and recycling of this raw material in the creation of new products. The final solution of the project was the creation of a line of cutting boards for the kitchen, proposed by the project "Árvore de Minas". Thus, the techniques of artisanal carpentry were used as a source of creative inspiration, aimed at valuing and rescuing the manufacturing production very present at the beginning of the history of the city of Ubá as a furniture hub.

Keywords: design; wood; recycling; ecodesign; handmade

\section{Referências bibliográficas}

ABIMÓVEL (Associação Brasileira das Indústrias do Mobiliário). Desenvolvendo e integrando a Indústria Brasileira do Mobiliário. Disponível em: https://www2.camara.leg.br/atividadelegislativa/comissoes/comissoes-temporarias/especiais/55a-legislatura/pl-8456-17-altera-a-cargatributaria/documentos/audiencias-publicas/abimovel. Acesso em: 10 de mar., 2019.

ARRUDA, Glória L.R.C de. 0 Design na indústria moveleira brasileira e seus aspectos sustentáveis: estudo de caso no pólo moveleiro de Arapongas-Pr. 2009. Dissertação (Mestrado em Arquitetura) -Faculdade de Arquitetura, Artes e Comunicação - FAAC, - Universidade Estadual Paulista "Júlio de Mesquita Filho", Bauru, 2009.

BAXTER, M. Projeto de Produto. 2. ed.. São Paulo: Edgard Blücher, 2003.

BATISTA, Henrique Gomes; NETO, João Sorima. Estratégia internacional das empresas é ameaçada pela política ambiental do governo: indústrias com reconhecimento global por práticas sustentáveis passaram a ser indagadas sobre práticas que põem em risco a preservação da Amazônia. O GLOBO, São Paulo, 12 de jul. de 2020. Disponível em: 
$<$ https://oglobo.globo.com/economia/estrategia-internacional-das-empresas-ameacada-pela-politicaambiental-do-governo-24528674 >. Acesso em: 02 de ago. e 2020.

BLAINEY, Geoffrey. Uma Breve História do Mundo. Curitiba: Fundamento, 2007.

BÜRDEK, B. E. História, teoria e prática do design de produtos. São Paulo: Edgard Blücher, 2006.

CARNEIRO, Henrique. Comida e sociedade: significados sociais na história da alimentação. História: Questões \& Debates, Curitiba, n. 42, p. 71-80, 2005. Editora UFPR.

CUNHA, Joana. 'Não há floresta em pé se ficarmos sentados', diz presidente da Natura: para João Paulo Ferreira, debate ambiental avança no meio empresarial, mas falta diálogo. Folha de São Paulo, 24 de nov. de 2019. Disponível em:

<https://www1.folha.uol.com.br/colunas/painelsa/2019/11/nao-ha-floresta-em-pe-se-ficarmos-ficarsentados-diz-presidente-da-natura.shtml?aff_source=56d95533a8284936a374e3a6da3d7996 > . Acesso em: 02 de ago. de 2020.

FREDERICO, Renata Leite Raposo. MÓDOLO, Cristiane Machado. Identidade cultural nas imagens da mídia especializada em gastronomia. Disponível em: https://www3.faac.unesp.br/anais-comunicacao/textos/23.pdf. Acesso em 02, de ago. de 2020. GALVÃO, Pedro. Mercado Novo é revitalizado e ganha lojas de quitutes, bar e restaurante. Uai, 18 de jan., 2019. Disponível: https://www.uai.com.br/app/noticia/gastronomia/2019/01/18/noticiasgastronomia,240355/mercado-novo-e-revitalizado-e-ganha-lojas-de-quitutes-bar-e-restauran.shtml.

GAZETA DO POVO. É preciso transformar os "Carlitos". 22 de jun., 2019. Disponível em: https://www.gazetadopovo.com.br/opiniao/artigos/e-preciso-transformar-os-carlitos/. Acesso em: 22 de jun., de 2020.

GIL, Marisa Adán. Millennials já são maioria da população do país e $50 \%$ da força de trabalho: $\mathrm{s}$ dados estão em pesquisa realizada pelo Itaú BBA sobre o perfil de consumo da Geração Y no Brasil; até 2030, assalariados devem chegar a 70\%. O GLOBO, 24, de set. de 2019.

GONZAGA, Armando Luiz. Madeira: uso e conservação. Brasília, DF: IPHAN/MONUMENTA, 2006. Disponível em:

<http://portal.iphan.gov.br/uploads/publicacao/CadTec6_MadeiraUsoEConservacao.pdf>. Acesso em: 02, de ago de 2020.

HESKETT, John. Desenho industrial. 4ª ed. Rio de Janeiro: José Olympio, 2012.

IBGE. População no último censo. 2010. Disponível em:

<https://cidades.ibge.gov.br/brasil/mg/uba/panorama>. Acesso em: 10, de abril de 2019.

HOBSBAWM, Eric J. Da Revolução Industrial inglesa ao imperialismo. (5a. ed.). Rio de Janeiro: Forense Universitária, 2003. ISBN 85-218-0272-2.

MANZINI, EZio; VEZZOLI, Carlo. 0 desenvolvimento de produtos sustentáveis: os requisitos ambientais dos produtos industriais. São Paulo: EdUSP, 2008.

MILLENNIALMARKETING. Who are millennials? Disponível em:

<http://www.millennialmarketing.com/who-are-millennials/>. Acesso em: 12, de ago. de 2019.

PAPANEK, Victor. Arquitectura e design: ecologia e ética. Lisboa: Edições 70, 2002.

PAZMINO, Ana Verônica. Como se cria: 40 métodos para design de produtos. São Paulo: Edgard. Blucher, 2015.

PAZZINATO, Alceu L.; SENISE, Maria Helena V. História moderna e contemporânea. São Paulo: Editora Ática, 2004.

SANTOS, B.B.M.D Os projetos de trabalho em ação. Rio de Janeiro. RJ : Mauad Editora LTDA, 2013.

TEIXEIRA, Déa Lúcia Pimentel; SOUZA, Maria Carolina A. F. de. Organização do processo de trabalho na evolução do capitalismo. Rev. adm. empres. vol.25 no.4 São Paulo Oct./Dec. 1985. Disponível em: <https://doi.org/10.1590/S0034-75901985000400007>. 